\title{
Efficacy of Intravitreal Dexamethasone Implant in Different Patterns of Diabetic Macular Edema
}

\author{
Claudio Furino, MD, PHD ${ }^{1}$; Alfredo Niro, MD, PHD²; Michele Reibaldi, MD, PHD 3 \\ Francesco Boscia, MD ${ }^{4}$; Giovanni Alessio, MD ${ }^{1}$ \\ ${ }^{1}$ Department of Medical Science, Neuroscience and Sense Organs, Eye Clinic, University of Bari, Bari, Italy \\ ${ }^{2}$ Eye Clinic, Hospital "S. G. MOSCATI", ASL TA, Taranto, Italy \\ ${ }^{3}$ Eye Clinic, University of Catania, Catania, Italy \\ ${ }^{4}$ Department of Surgical, Microsurgical and Medical Sciences, Eye Clinic, University of Sassari, Sassari, Italy \\ ORCID: \\ Claudio Furino: https://orcid.org/0000-0003-0254-7432
}

\section{Abstract}

Purpose: Different patterns of diabetic macular edema (DME) suggest different pathogenesis and drug response. We evaluated the outcomes after intravitreal dexamethasone (DEX) implant for DME with or without serous retinal detachment (SRD). Methods: In this retrospective study, 22 naïve patients (23 eyes) with DME who underwent a single DEX implant were evaluated. Based on the optical coherence tomographic pattern of DME, 12 eyes had a cystoid macular edema pattern (Group 1) and 11 eyes had an SRD pattern (Group 2). The best-corrected visual acuity (BCVA), central retinal thickness (CRT), central retinal volume (CRV), SRD height (SRDh), and intraocular pressure (IOP) were recorded before and at two and four months after the treatment.

Results: There were no significant differences between the groups regarding demographic, clinical data and outcomes at baseline. In Group 1, the CRT and CRV significantly decreased at two months $(P=0.002$ and $P=0.01$, respectively), while the BCVA significantly improved at four months $(P=0.03)$. In Group 2 , the CRT and CRV significantly improved $(P<0.01$ and $P \leq 0.01$, respectively) during the follow-up period. At four months, both groups showed a recurrence of DME, Group 1 in particular (two-month CRT reduction, $-149 \pm 127 \mu \mathrm{m}$ vs four-month CRT reduction, $-72 \pm 174 \mu \mathrm{m} ; P=0.04)$. The mean reduction in CRV was significantly different at four months (Group 1, $-0.49 \pm 1.7$ $\mathrm{mm}^{3}$ vs Group 2, $\left.-1.3 \pm 1.3 \mathrm{~mm}^{3} ; P=0.04\right)$. In Group 2, the SRDh significantly decreased at two $(P=0.01)$ and four months $(P=0.01)$. Four cases with elevated IOP were managed. Conclusion: DEX implants were found to be effective in different patterns of DME. The SRD pattern may predict a longer-lasting morphologic efficacy.

Keywords: Dexamethasone Implant; Diabetic Macular Edema; OCT, Ozurdex ${ }^{\circledR}$; Subretinal Detachment

J Ophthalmic Vis Res 2020; 15 (4): 524-530

Correspondence to:

Claudio Furino, MD, PhD. Department of Medical Science, Neuroscience and Sense Organs, Eye Clinic, University of Bari, Piazza G. Cesare, 1170124 Bari, Italy. Email: claudiofurino@gmail.com

Received: 10-07-2019 Accepted: 05-08-2020

\section{Access this article online}

Website: https://knepublishing.com/index.php/JOVR

DOI: 10.18502/jovr.v15i4.7787

\section{INTRODUCTION}

Diabetic macular edema (DME) is the main cause of visual loss in diabetic patients. ${ }^{[1]}$ Different patterns

This is an open access journal, and articles are distributed under the terms of the Creative Commons Attribution-NonCommercial-ShareAlike 4.0 License, which allows others to remix, tweak, and build upon the work non-commercially, as long as appropriate credit is given and the new creations are licensed under the identical terms.

How to cite this article: Furino $C$, Niro A, Reibaldi M, Boscia F, Alessio G. Efficacy of Intravitreal Dexamethasone Implant in Different Patterns of Diabetic Macular Edema. J Ophthalmic Vis Res 2020;15:524-530. 
of nontractional macular edema have been revealed by optical coherence tomography (OCT) including sponge-like swelling, cystoid macular edema (CME), and serous retinal detachment (SRD). ${ }^{[2,3]}$ However, many eyes show more than one macular edema pattern in OCT. ${ }^{[2-6]}$ Different patterns of CME and SRD suggest different mechanisms of pathogenesis, ${ }^{[7-9]}$ which lead us to speculate various possible mechanisms of drug action. At present, several pharmacologic approaches are effective for treating DME, including intravitreal anti-vascular endothelial growth factor (VEGF) agents and intravitreal steroid implants. Corticosteroids are effective owing to their anti-inflammatory, antiangiogenic, and blood retinal barrier (BRB)stabilizing properties. ${ }^{[10]}$ In DME, the sustainedrelease intravitreal dexamethasone (DEX) implant was observed to be effective, requiring less frequent repeated injections as compared to anti-VEGFs, with common complications such as intraocular pressure (IOP) elevation and cataract formation/progression. ${ }^{[1]}$ In an analysis of data from a Phase II randomized controlled study (NCT00035906), DEX implants were found to display a similar efficacy in different patterns of DME without reference to SRD. ${ }^{[12]}$ The purpose of this study was to analyze the safety and efficacy of a intravitreal DEX implant in the treatment of diabetic CME with and without subretinal fluid.

\section{METHODS}

In this retrospective study, 23 eyes of 22 diabetic patients with clinically significant DME, as defined by the Early Treatment Diabetic Retinopathy Study (ETDRS), ${ }^{[13]}$ were included. Nontractional DME involving the central macula $1 \mathrm{~mm}$ central subfield thickness in the OCT-modified ETDRS grid) with a thickness $\geq 300 \mu \mathrm{m}$ was considered. Eyes with diffuse spongiform edema, advanced proliferative diabetic retinopathy, other retinal pathologies, or those who underwent previous laser photocoagulation within six months, ocular surgery, or intravitreal injection were excluded. Patient data including age, sex, duration of diabetes, and baseline glycated hemoglobin (HbA1c) levels were recorded. A complete ophthalmologic examination including bestcorrected visual acuity (BCVA) measurement, slit-lamp examination, IOP measurement, and fundus examination were performed before as well as two and four months after the treatment. BCVA measured by ETDRS chart was converted into a LogMAR notation for statistical analysis. At each visit, five HD-lines and macular cube $(512 \times 128)$ OCT scans were performed using the Cirrus SD-OCT 4000 (Carl Zeiss Meditec, Inc., Dublin, California, USA). The eligible eyes were categorized into two groups according to the OCT pattern of macular edema: Group 1 with CME consisting of intraretinal hyporeflective cystoid spaces and Group 2 with intraretinal edema associated with SRD. The central retinal thickness (CRT, $\mu \mathrm{m})$ at the foveal site and the central retinal volume (CRV, $\mathrm{mm}^{3}$ ) for each group were recorded. In Group 2, the maximum SRD height (SRDh, $\mu \mathrm{m}$ ) at the fixation point was measured manually using calipers in the "High Definition Image Analysis" mode (HD-OCT Software version 5, Cirrus SD-OCT 4000, Carl Zeiss Meditec, Inc, Dublin, California, USA) and was defined as the average distance between the retinal pigment epithelium (RPE) and the outer neurosensory retinal surface on central vertical and horizontal scans. All OCT scans and measurements were collected by the same observer.

All patients received a single dose $(700$ $\mu \mathrm{g})$ of DEX as a sustained-release intravitreal implant (Ozurdex ${ }^{\circledR}$, Allergan, Inc., Irvine, CA, USA). The mean BCVA, CRT, and CRV changes were analyzed at all visits.

The study was approved by the Institutional Review Board (IRB) of an eye clinic in Italy and adhered to the tenets of the Declaration of Helsinki. An IRB approved informed consent was obtained from all patients.

Quantitative data are presented as mean \pm standard deviation. Data from the same sample were analyzed using the Wilcoxon test. The differences between the two samples before and after the implantation were assessed using Fisher's test for categorical variables and the MannWhitney test for quantitative variables. The sample size was determined considering a confidence level of $95 \%$ and a confidence interval of 20 . A $p$-value $<0.05$ was considered as statistically significant. Statistical analysis was performed using GraphPad Prism, version 5.

\section{RESULTS}

Twenty-three naïve eyes of 22 patients with type 2 diabetes mellitus were included. The patients 
included 6 (27.3\%) women and 16 (72.7\%) men, with a mean age of $62 \pm 7.7$ years (range, 42-76 years). The mean overall diabetes duration was 6.4 \pm 3.4 years, and the $\mathrm{HbA} 1 \mathrm{C}$ mean value was 7.5 $\pm 1 \%$ (Table 1). All eyes were phakic with a mild-tomoderate grade cataract. Of the 23 eyes, 12 (52\%) had a CME pattern (Group 1) and 11 (48\%) had an SRD pattern (Group 2) on OCT analysis.

There was no statistically significant difference between the two groups in terms of age, sex, mean diabetes duration, or $\mathrm{HbA1C}$ value (Table 1).

The mean overall BCVA, CRT, and CRV improved significantly at two and four months after the DEX implantation (Table 2).

In Group 1, the mean BCVA improved from 0.66 \pm 0.34 LogMAR (Snellen equivalent of 20/91) at baseline to $0.37 \pm 0.17$ LogMAR (Snellen equivalent of 20/47) $(P=0.06)$ at two months and $0.32 \pm$ 0.19 LogMAR (Snellen equivalent of 20/42) at four months $(P=0.03)$. The mean CRT decreased from $478 \pm 147 \mu \mathrm{m}$ at baseline to $329 \pm 100 \mu \mathrm{m}$ at two months $(P=0.002)$ and $405 \pm 132 \mu \mathrm{m}$ at four months $(P=0.15)$. The mean CRV decreased from $12.8 \pm 1.9 \mu \mathrm{m}^{3}$ at baseline to $11.1 \pm 1.5 \mathrm{~mm}^{3}$ at two months $(P=0.01)$ and $12.3 \pm 1.7 \mathrm{~mm}^{3}$ at four months $(P=0.58$; Table 2$)$.

In Group 2, the mean BCVA improved from $0.65 \pm 0.43$ LogMAR (Snellen equivalent of 20/89) at baseline to $0.42 \pm 0.23$ LogMAR (Snellen equivalent of 20/53) at two months $(P=0.35)$ and $0.39 \pm 0.24$ LogMAR (Snellen equivalent of 20/49) at four months $(P=0.39)$. The mean CRT decreased from $542 \pm 131 \mu \mathrm{m}$ at baseline to $347 \pm 97 \mu \mathrm{m}$ at two months $(P=0.006)$ and $393 \pm 109 \mu \mathrm{m}$ at four months $(P=0.003)$. The mean CRV decreased from $13.7 \pm 1.8 \mathrm{~mm}^{3}$ at baseline to $11.6 \pm 1.5 \mathrm{~mm}^{3}$ at two months $(P=0.007)$ and $12.4 \pm 1.0 \mathrm{~mm}^{3}$ at four months $(P=0.01$; Table 2$)$. At baseline and over follow-up, no significant difference was observed in the functional and morphologic outcomes among the groups $(P>0.05)$ (Table 2$)$.

The overall CRT reduction over two months was significantly larger than the reduction observed over four months $(P=0.03)$. In the same way, the overall CRV reduction over two months was significantly larger than the reduction observed over four months $(P=0.02)$. The difference between the mean change in BCVA over the first two months and the overall four months was not statistically significant $(P=0.26)$. At the last follow-up, an improvement of three lines or more was reported in 12 (52\%) patients; 7 (58\%) in the CME group and five (45\%) in the SRD group ( $P=$ 0.6). The difference between BCVA improvement over the first two and the overall four months within each group and among the groups was not statistically significant $(P>0.05)$. In each group, mainly in Group 1, the mean CRT and CRV reduction after two months of follow-up were larger than those observed four months after the implantation. The mean reduction in CRV was significantly different among the groups four months after the implantation $(P=0.04$ ) (Table 3).

In Group 2, the SRDh significantly decreased at months $2(P=0.01)$ and $4(P=0.01)$ without a significant difference in the mean change at two time points (Table 4). In Group 2, a total resolution of SRD was reported in three (27.3\%) eyes and two (18.2\%) eyes at two and four months, respectively. Of the three eyes with a resolution of SRD at two months, only one (9\%) remained without any SRD at four months. All eyes had a resolution of subretinal detachment without resolution of overlying neuroretinal edema.

Three eyes (13\%) had a mild IOP elevation $(<25$ $\mathrm{mmHg}$ ), and only one case (3.8\%) developed a high IOP elevation ( $30 \mathrm{mmHg}$ ). All cases were medically managed. No other ocular adverse events were reported.

\section{DISCUSSION}

OCT is the most useful tool for diagnosing and monitoring DME. Based on the OCT features of DME, we focused our study on the therapeutic efficacy of Ozurdex ${ }^{\circledR}$ on two different patterns of nontractional DME, namely, the cystoid pattern and the retinal detachment pattern that occur in patients with diabetic retinopathy with a prevalence from $47-55 \%^{[2,4]}$ and from 15$31 \%,{ }^{[2,5,6]}$ respectively. In our study, both systemic risk factors and morpho-functional data at baseline did not show significant differences among the two OCT-pattern groups, allowing us to evaluate the effectiveness of the drug in two similar populations. Moreover, Vujosevic et al reported that systemic parameters, such as glycemic control and arterial hypertension, did not correlate with the presence of subretinal detachment, thus suggesting that ocular factors might be more important in the development of the features of DME. ${ }^{[14]}$

Intravitreal DEX implants have demonstrated efficacy in the treatment of DME, causing both 
Table 1. Characteristics of patients and their systemic risk factors.

\begin{tabular}{lcccc}
\hline & Total & Group 1 & Group 2 & P-value* \\
\hline Female/male (No. of eyes) & $6 / 16$ & $4 / 8$ & $12 / 8$ & $0.43^{\dagger}$ \\
& 23 & 11 & $64 \pm 9$ \\
Mean age (yrs) \pm SD & $65 \pm 10$ & $67 \pm 10$ & $7.2 \pm 4.1$ & $4.5 \pm 1.6$ \\
Mean diabetes duration (yrs) \pm SD & $6.4 \pm 3.4$ & $7.5 \pm 0.9$ & $7.4 \pm 0.8$ & 0.06 \\
HbA1C (\%) & $7.5 \pm 1$ & 0.78
\end{tabular}

SD, standard deviation; HbA1C, glycosylated hemoglobin; DRT, diffuse retinal thickening; CME, cystoid macular edema; SRD, serous retinal detachment

${ }^{*} P$-value (Mann-Whitney test); ${ }^{\dagger} P$-value (Fisher test) between Groups 1 and $2 ; P$-values $<0.05$ were considered statistically significant

Table 2. The mean BCVA, CRT, and CRV before and after the treatment at months 2 and 4

\begin{tabular}{|c|c|c|c|c|c|}
\hline & & Total & Group 1 & Group 2 & P-value* \\
\hline Baseline & $\begin{array}{c}\text { BCVA }(\log M A R \pm S D) \\
\text { CRT }(\mu \mathrm{m} \pm \mathrm{SD}) \\
\text { CRV }\left(\mathrm{mm}^{3} \pm \mathrm{SD}\right)\end{array}$ & $\begin{array}{l}0.66 \pm 0.38 \\
508 \pm 141 \\
13.2 \pm 1.9\end{array}$ & $\begin{array}{c}0.66 \pm 0.34 \\
478 \pm 147 \\
12.8 \pm 1.9\end{array}$ & $\begin{array}{l}0.65 \pm 0.43 \\
542 \pm 131 \\
13.7 \pm 1.8\end{array}$ & $\begin{array}{l}0.38 \\
0.38 \\
0.32\end{array}$ \\
\hline \multirow[t]{3}{*}{$2^{\text {nd }}$ month } & $\underset{P^{\dagger}}{\mathrm{BCVA}}(\log \mathrm{MAR} \pm \mathrm{SD})$ & $\begin{array}{l}0.39 \pm 0.19 \\
\mathbf{0 . 0 3}\end{array}$ & $\begin{array}{l}0.37 \pm 0.17 \\
0.06\end{array}$ & $\begin{array}{l}0.42 \pm 0.23 \\
0.26\end{array}$ & 0.58 \\
\hline & 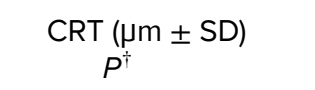 & $\begin{array}{l}337 \pm 97 \\
<0.0001\end{array}$ & $\begin{array}{c}329 \pm 100 \\
0.002\end{array}$ & $\begin{array}{c}347 \pm 97 \\
0.006\end{array}$ & 0.77 \\
\hline & $\underset{P^{\dagger}}{\mathrm{CRV}}\left(\mathrm{mm}^{3} \pm \mathrm{SD}\right)$ & $\begin{array}{l}11.4 \pm 1.5 \\
0.0002\end{array}$ & $\begin{array}{c}11.1 \pm 1.5 \\
0.01\end{array}$ & $\begin{array}{l}11.6 \pm 1.5 \\
\mathbf{0 . 0 0 7}\end{array}$ & 0.29 \\
\hline \multirow[t]{3}{*}{$4^{\text {th }}$ month } & $\underset{P^{\dagger}}{\mathrm{BCVA}}(\log \mathrm{MAR} \pm \mathrm{SD})$ & $\begin{array}{l}0.36 \pm 0.21 \\
0.02\end{array}$ & $\begin{array}{l}0.32 \pm 0.19 \\
\mathbf{0 . 0 3}\end{array}$ & $\begin{array}{l}0.39 \pm 0.24 \\
0.19\end{array}$ & 0.44 \\
\hline & $\left.\underset{P^{\dagger}}{\mathrm{CRT}} \underset{(\mu \mathrm{m}}{ } \pm \mathrm{SD}\right)$ & $\begin{array}{l}398 \pm 119 \\
0.001\end{array}$ & $\begin{array}{l}401 \pm 133 \\
0.15\end{array}$ & $\begin{array}{l}393 \pm 109 \\
0.003\end{array}$ & 0.97 \\
\hline & $\underset{P^{\dagger}}{\mathrm{CRV}}\left(\mathrm{mm}^{3} \pm \mathrm{SD}\right)$ & $\begin{array}{c}12.4 \pm 1.4 \\
0.001\end{array}$ & $\begin{array}{l}12.3 \pm 1.7 \\
0.58\end{array}$ & $\begin{array}{l}12.4 \pm 1.0 \\
\mathbf{0 . 0 1}\end{array}$ & 0.64 \\
\hline
\end{tabular}

BCVA, best corrected visual acuity; logMAR, logarithm of minimum angle of resolution; SD, standart deviation; CRT, central retinal thickness; CRV, central retinal volume; CME, cystoid macular edema; SRD, serous retinal detachment ${ }^{*} P$-values (Mann-Whitney test), comparison between Groups 1 and $2 ;{ }^{\dagger} P$-value (Wilcoxon test), comparison between baseline and follow-up data (at two and four months) for all patients, and within single groups; $P$-value $<0.05$ was considered statistically significant

substantial improvement in BCVA and significant reduction of $C R{ }^{[11]}$ In the current study, the mean overall BCVA showed a statistically significant improvement with a larger increase at four months after the DEX implant. An improvement of three lines or more was reported in 52\% of patients without differences among the groups. These results are in line with those previously published. ${ }^{[11,15-19]}$ We observed that the mean BCVA of the SRD group remained lower than that of the group with a cystoid pattern over the follow-up period, and that the single-group analysis showed an equal trend of functional improvement without a significant difference in the mean functional recovery between the groups, as previously reported. ${ }^{[20]}$ However, only the eyes with CME showed a significant improvement in visual acuity at four months. Gaucher et $\mathrm{al}^{[21]}$ suggested that the presence of subretinal fluid does not seem to be a negative prognostic factor, 
Table 3. The mean change of BCVA, CRT, and CRV over four months

\begin{tabular}{|c|c|c|c|c|}
\hline & Total & Group 1 (CME) & Group 2 (SRD) & P-value* \\
\hline $\begin{array}{l}\text { BCVA change (0-2 month) } \\
\text { (logMAR } \pm \text { SD) }\end{array}$ & $-0.31 \pm 0.51$ & $-0.29 \pm 0.46$ & $-0.23 \pm 0.64$ & 0.71 \\
\hline $\begin{array}{l}\text { CRT change (0-2 month) } \\
(\mu \mathrm{m} \pm \mathrm{SD})\end{array}$ & $-171 \pm 135$ & $-149 \pm 127$ & $-195 \pm 146$ & 0.34 \\
\hline $\begin{array}{l}\text { CRV change (0-2 month) } \\
\left(\mu \mathrm{m}^{3} \pm \mathrm{SD}\right)\end{array}$ & $-1.8 \pm 1.76$ & $-1.6 \pm 1.7$ & $-2.1 \pm 1.9$ & 0.56 \\
\hline $\begin{array}{l}\text { Mean BCVA change } \\
(0-4 \text { month) }(\text { logMAR } \pm S D) \\
P^{\dagger}\end{array}$ & $-0.30 \pm 0.54$ & $\begin{array}{c}-0.33 \pm 0.46 \\
0.21\end{array}$ & $\begin{array}{c}-0.26 \pm 0.64 \\
0.56\end{array}$ & 0.64 \\
\hline $\begin{array}{l}\text { Mean CRT change } \\
(0-4 \text { month) }(\mu \mathrm{m} \pm \mathrm{SD}) \\
P^{\dagger}\end{array}$ & $\begin{array}{c}-109 \pm 150 \\
\mathbf{0 . 0 3}\end{array}$ & $\begin{array}{c}-72 \pm 174 \\
0.04\end{array}$ & $\begin{array}{c}-149 \pm 123 \\
0.37\end{array}$ & 0.06 \\
\hline $\begin{array}{l}\text { Mean CRV change } \\
(0-4 \text { month })\left(\mu \mathrm{m}^{3} \pm \mathrm{SD}\right) \\
P^{\dagger}\end{array}$ & $-0.90 \pm 1.56$ & $-0.49 \pm 1.7$ & $\begin{array}{c}-1.3 \pm 1.3 \\
0.10\end{array}$ & 0.04 \\
\hline
\end{tabular}

BCVA, best corrected visual acuity; logMAR, logarithm of minimum angle of resolution; SD, standard deviation; CRT, central retinal thickness; CRV, central retinal volume; CME, cystoid macular edema; SRD, serous retinal detachment ${ }^{*} P$-value (Mann-Whitney test), comparison between Group 1 and Group 2; ${ }^{\dagger} P$-value (Wilcoxon test), comparison within single groups; $P$-values $<0.05$ were considered statistically significant

Table 4. Serous Retinal Detachment height changes over follow-up

\begin{tabular}{lccc}
\hline Group 2 (11 Eyes) & Baseline & $2^{\text {nd }}$ month & $4^{\text {th }}$ month \\
\hline SRDh $(\mu \mathrm{m} \pm \mathrm{SD})$ & $146 \pm 82$ & $72 \pm 75$ & $90 \pm 61$ \\
$P^{\dagger}$ & & 0.01 & 0.01 \\
SRDh change $(\mu \mathrm{m} \pm \mathrm{SD})$ & $-74 \pm 71$ & $-55 \pm 59$ & 0.38 \\
\hline
\end{tabular}

SRDh, serous retinal detachment height; SD, standard deviation

* $P$-value (Wilcoxon test), comparison between SRDh changes at different follow-ups;

†P-value (Wilcoxon test), comparison with baseline; $P$-value $<0.05$ was considered statistically significant

while other authors have shown that the SRD pattern had a worse prognosis on functional recovery after treatment as compared to the CME pattern ${ }^{[22-26]}$ considering that subretinal fluid could induce photoreceptor degradation which would decrease its metabolism. ${ }^{[27]}$

Overall, the mean CRT and CRV showed a statistically significant reduction at all follow-up visits. The largest reduction in CRT and CRV was observed at two months when DEX reached the highest concentration in the vitreous humor. ${ }^{[28]}$

In both groups, we observed a reduction in the mean CRT and CRV at two months, followed by a moderate increase at four months. The group with a cystoid pattern showed less reduction and a significant recurrence of edema over follow-up, while the eyes with subretinal fluid showed a larger CRT and CRV reduction at two and four months, and a lower recurrence of edema than the eyes with cystoid edema. Deepening the analysis, the SRDh significantly decreased at all followup visits, showing the same trend of CRT and CRV. In the SRD group, four patients showed a total resolution of subretinal detachment without resolution of overlying neuroretinal edema at different follow-up visits. The resolution of the subretinal fluid could appear despite persistence or worsening of the neuroretinal swelling and preceding or following its resolution. ${ }^{[21]}$ Horii et al ${ }^{[9]}$ suggested several mechanisms causing different OCT patterns of DME due to BRB breakdown, including the movement of serum proteins, lipids, 
blood constituents, and small molecules from or to the cystoid spaces. The inner BRB dysfunction, at tight junctions and transendothelial vesicular transport in the capillary endothelial cells, leads to neuroretinal fluid accumulation causing edema. ${ }^{[7]}$ In the cystoid pattern of DME, the occurrence of cysts from degenerating retinal Müller cells remains a subject of debate, but their role in the formation of this pattern is certain. ${ }^{[29]}$ An SRD pattern has been postulated to be the result of the movement of fluid from the retina to the subretinal space. ${ }^{[8]}$ The leakage of albumin into the subretinal space brings out fluid, but this does not explain the presence of retinal detachment when the subretinal osmotic pressure equilibrates with the vitreal space. ${ }^{[30,31]}$ Other mechanisms can be involved in favoring subretinal fluid accumulation and might be targeted by steroid therapy. In this regard, external limiting membrane dysfunction can promote the diffusion of proteins into the subretinal space, ${ }^{[32-35]}$ RPE pump failure found in diabetics and favored by a hypoxic state, ${ }^{[36,37]}$ and reduction of choroidal flow that would induce RPE dysfunction. ${ }^{[38]}$

Corticosteroids have a wide spectrum of antiinflammatory and anti-edema effects. In particular, these effects include the stabilization of the BRB and increasing the integrity of tight junctions of the endothelial cells of blood vessels, leading to reduction of exudation and downregulation of inflammation. ${ }^{[39]}$ Therefore, our data suggest a greater and more lasting improvement in the morphologic outcomes of CRT and CRV in eyes with an SRD pattern than eyes with CME features after a DEX implant, probably due to a greater stabilization of the outer BRB. Regarding safety, few cases $(4 / 23,17.4 \%)$ had an IOP elevation that could be managed pharmacologically without any surgical approach.

This study has several limitations, including its retrospective, short-term, open-label, uncontrolled nature involving a relatively small number of eyes, which precluded any evaluation of longterm efficacy and need for Ozurdex ${ }^{\circledR}$ reinjection. We selected only naïve patients with the aim of evaluating the therapeutic efficacy of DEX implant as the first treatment, even though we are aware that these eyes are more responsive than eyes with DME refractory to anti-VEGF. ${ }^{[40]}$ A comparative analysis of the efficacy of DEX on different OCT patterns of DME between naïve and refractory eyes should be performed.
In conclusion, the anatomical and functional improvements reported in our work could suggest a different therapeutic response of different patterns of DME to slow-release intravitreal DEX implants. Our findings are worthy of investigation in order to develop customized therapies for different tomographic patterns of DME.

\section{Financial Support and Sponsorship}

None.

\section{Conflicts of Interest}

There are no conflicts of interest.

\section{REFERENCES}

1. Yau JW, Rogers SL, Kawasaki R, Lamoureux EL, Kowalski JW, Bek T, et al. Global prevalence and major risk factors of diabetic retinopathy. Diabetes Care 2012;35:556-564.

2. Otani T, Kishi S, Maruyama Y. Patterns of diabetic macular edema with optical coherence tomography. Am J Ophthalmol 1999;127:688-693.

3. Trichonas G, Kaiser PK. Optical coherence tomography imaging of macular oedema. Br J Ophthalmol 2014;98:2429.

4. Kim BY, Smith SD, Kaiser PK. Optical coherence tomographic patterns of diabetic macular edema. Am J Ophthalmol 2006;142:405-412.

5. Catier A, Tadayoni R, Paques M, Erginay A, Haouchine B, Gaudric A, et al. Characterization of macular edema from various etiologies by optical coherence tomography. Am J Ophthalmol 2005;140:200-206.

6. Ozdemir H, Karacorlu M, Karacorlu S. Serous macular detachment in diabetic cystoid macular oedema. Acta Ophthalmol Scan 2005;83:63-66.

7. Antonetti DA, Barber AJ, Khin S, Lieth E, Tarbell JM, Gardner TW. Vascular permeability in experimental diabetes is associated with reduced endothelial occludin content: vascular endothelial growth factor decreases occludin in retinal endothelial cells. Penn State Retina Research Group. Diabetes 1998;47:1953-1959.

8. Otani T, Kishi S. Tomographic assessment of vitreous surgery for diabetic macular edema. Am J Ophthalmol 2000;129:487-494.

9. Horii T, Murakami T, Nishijima K, Akagi T, Uji A, Arakawa N, et al. Relationship between fluorescein pooling and optical coherence tomographic reflectivity of cystoid spaces in diabetic macular edema. Ophthalmology 2012;119:10471055.

10. Ford JA, Lois N, Royle P, Clar C, Shyangdan D, Waugh $\mathrm{N}$. Current treatments in diabetic macular oedema: systematic review and meta-analysis. BMJ Open 2013;1:3.

11. Boyer DS, Yoon YH, Belfort R Jr, Bandello F, Maturi RK, Augustin AJ, et al. Ozurdex MEAD Study Group. Threeyear, randomized, sham-controlled trial of dexamethasone intravitreal implant in patients with diabetic macular edema. Ophthalmology 2014;121:1904-1914. 
12. Kuppermann BD, Chou C, Weinberg DV, Whitcup SM, Haller JA, Blumenkranz MS, et al. Intravitreous dexamethasone effects on different patterns of diabetic macular edema. Arch Ophthalmol 2010;128:642-643.

13. Photocoagulation for diabetic macular edema. Early Treatment Diabetic Retinopathy Study report number 1. Early Treatment Diabetic Retinopathy Study research group. Arch Ophthalmol 1985;103:1796-1806.

14. Vujosevic S, Torresin T, Berton M, Bini S, Convento E, Midena E. Diabetic macular edema with and without subfoveal neuroretinal detachment: two different morphological and functional entities. Am J Ophthalmol 2017;181:149-155.

15. Guigou S, Pommier S, Meyer F, Hajjar C, Merite PY, Parrat E, et al. Efficacy and safety of intravitreal dexamethasone implant in patients with diabetic macular edema. Ophthalmologica 2015;233:169-75.

16. Mastropasqua R, Toto L, Borrelli E, Di Antonio L, De Nicola C, Mastrocola A, et al. Morphology and function over a one-year follow up period after intravitreal dexamethasone implant (Ozurdex) in patients with diabetic macular edema. PLOS ONE 2015;10:e0145663.

17. Matonti F, Pommier S, Meyer F, Hajjar C, Merite PY, Parrat E, et al. Long-term efficacy and safety of intravitreal dexamethasone implant for the treatment of diabetic macular edema. Eur J Ophthalmol 2016;26:454-459.

18. Aknin I, Melki L. Longitudinal study of sustained-release dexamethasone intravitreal implant in patients with diabetic macular edema. Ophthalmologica 2016;235:187188.

19. Pareja-Ríos A, Ruiz-de la Fuente-Rodríguez P, BonaqueGonzález S, López-Gálvez M, Lozano-López V, RomeroAroca P. Intravitreal dexamethasone implants for diabetic macular edema. Int J Ophthalmol 2018;11:77-82.

20. Castro-Navarro V, Cervera-Taulet E, Navarro-Palop C, Monferrer-Adsuara C, Hernández-Bel L, MonteroHernández J. Intravitreal dexamethasone implant Ozurde ${ }^{\circledR}$ in naïve and refractory patients with different subtypes of diabetic macular edema. BMC Ophthalmol 2019;19:15.

21. Gaucher D, Sebah C, Erginay A, Haouchine B, Tadayoni R, Gaudric A, et al. Optical coherence tomography features during the evolution of serous retinal detachment in patients with diabetic macular edema. Am J Ophthalmol 2008;145:289-296.

22. Kim M, Lee P, Kim Y, Yu SY, Kwak HW. Effect of intravitreal bevacizumab based on optical coherence tomography patterns of diabetic macular edema. Ophthalmologica 2011;226:138-144.

23. Shimura M, Yasuda K, Yasuda M, Nakazawa T. Visual outcome after intravitreal bevacizumab depends on the optical coherence tomographic patterns of patients with diffuse diabetic macular edema. Retina 2013;33:740-747.

24. Wu PC, Lai CH, Chen CL, Kuo CN. Optical coherence tomographic patterns in diabetic macula edema can predict the effects of intravitreal bevacizumab injection as primary treatment. J Ocul Pharmacol Ther 2012;28:59-64.

25. Roh MI, Kim JH, Kwon OW. Features of optical coherence tomography are predictive of visual outcomes after intravitreal bevacizumab injection for diabetic macular edema. Ophthalmologica 2010;224:374-380.
26. Shimura M, Yasuda K, Nakazawa T, Hirano Y, Sakamoto $\mathrm{T}$, Ogura $\mathrm{Y}$, et al. Visual outcome after intravitreal triamcinolone acetonide depends on optical coherence tomographic patterns in patients with diffuse diabetic macular edema. Retina 2011;31:748-754.

27. Murakami T, Nishijima K, Akagi T, Uji A, Horii $T$, Ueda-Arakawa $\mathrm{N}$, et al. Optical coherence tomographic reflectivity of photoreceptors beneath cystoid spaces in diabetic macular edema. Invest Ophthalmol Vis Sci 2012;53:1506-1511.

28. Chang-Lin JE, Attar M, Acheampong AA, Robinson MR, Whitcup SM, Kuppermann BD, et al. Pharmacokinetics and pharmacodynamics of a sustained-release dexamethasone intravitreal implant. Invest Ophthalmol Vis Sci 2011;52:80-86.

29. Daruich A, Matet A, Moulin A, Kowalczuk L, Nicolas M, Sellam A, et al. Mechanisms of macular edema: beyond the surface. Prog Retin Eye Res 2018;63:20-68.

30. Takeuchi A, Kricorian G, Marmor MF. Albumin movement out of the subretinal space after experimental retinal detachment. Invest Ophthalmol Vis Sci 1995;36:12981305.

31. Kang SW, Park CY, Ham DI. The correlation between fluorescein angiographic and optical coherence tomographic features in clinically significant diabetic macular edema. Am J Ophthalmol 2004;137:313-322.

32. Soliman W, Sander B, Jorgensen TM. Enhanced optical coherence patterns of diabetic macular oedema and their correlation with the pathophysiology. Acta Ophthalmol Scan 2007;85:613-617.

33. Augustin A, Loewenstein A, Kuppermann BD. Macular edema. General pathophysiology. Dev Ophthalmol 2010;47:10-26

34. Scholl S, Augustin A, Loewenstein A, Rizzo S, Kupperman B. General pathophysiology of macular edema. Eur J Ophthalmol 2011;21:10-19.

35. Xu HZ, Le YZ. Significance of outer blood-retina barrier breakdown in diabetes and ischemia. Invest Ophthalmol Vis Sci 2011;52:2160-2164.

36. Weinberger D, Fink-Cohen S, Gaton DD, Priel E, Yassur Y. Non-retinovascular leakage in diabetic maculopathy. $\mathrm{Br} \mathrm{J}$ Ophthalmol 1995;79:728-731.

37. Spaide R, Yannuzzi L. Manifestations and pathophysiology of serous detachment of the retinal pigment epithelium and retina. In: Marmor $\mathrm{M}$, Wolfensberger T, editors. The retinal pigment epithelium: function and disease. New York, New York: Oxford University Press, 1998:439-455.

38. Nagaoka T, Kitaya N, Sugawara R, Yokota H, Mori F, Hikichi T. Alteration of choroidal circulation in the foveal region in patients with type 2 diabetes. $\mathrm{Br} \mathrm{J}$ Ophthalmol 2004;88:1060-1063

39. Semeraro F, Morescalchi F, Cancarini A, Russo A, Rezzola $\mathrm{S}$, Costagliola C. Diabetic retinopathy, a vascular and inflammatory disease: therapeutic implications. Diabetes Metab 2019;45:517-527.

40. Iglicki M, Busch C, Zur D, Okada M, Mariussi M, Chhablani JK, et al. Dexamethasone implant for diabetic macular edema in naïve compared with refractory eyes: the International Retina Group real-life 24-month multicenter study. The IRGREL-DEX study. Retina 2019;39:44-51. 